\title{
Arriendo y desigualdad en las tierras altas de Jujuy (Argentina) a fines del siglo XIX*
}

\section{Resumen}

Las estructuras agrarias originadas en los procesos más generales de desarrollo capitalista y de redefinición de los derechos de propiedad del siglo XIX en la provincia argentina de Jujuy, resultaron favorables a la formación de importantes latifundios. La contracara de esa fuerte concentración de tierras fue la existencia de un amplio sector de la sociedad que compartía la condición de arrendatarios. De ahí que en este artículo nos proponemos estudiar a los arrendatarios como productores -la riqueza y los ingresos brutos procedentes de la explotación rural que tenían a su cargo- a fin de indagar su capacidad de remuneración, contrastándolos entre sí y con otras situaciones sociales. Para ello, analizamos dos casos que tratan el asunto de sus relaciones de producción en el arriendo. A partir de fuentes fiscales y censales de la década de 1890 que contienen datos de la actividad agropecuaria y de informes sobre la rentabilidad de los distintos productos de origen agrícola o ganaderos de la misma época, reconstruimos el ingreso bruto de esas unidades para cada uno de los actores involucrados en ellas y analizamos los niveles de desigualdad para ese conjunto social.

Palabras clave: Argentina, Jujuy, gran propiedad, arrendatarios, desigualdad.

Referencia para citar este artículo: FANDOS, Cecilia A (2016). "Arriendo y desigualdad en las tierras altas de Jujuy (Argentina) a fines del siglo XIX”, en Anuario de Historia Regional y de las Frontera. 21 (1). pp. 133-157.

Fecha de recepción: 25/02/2015

Fecha de aceptación: 08/06/2015

Cecilia A. Fandos: Doctora en Historia, Universidad Nacional de Tucumán. Investigadora adjunta del CONICET. Profesora asociada ordinaria de la Cátedra de Historia Económica y Social de la Facultad de Ciencias Económicas de la Universidad Nacional de Jujuy. Correo electrónico: cecifandos@gmail.com.

\footnotetext{
*Artículo de investigación científica, resultado de los avances de investigación del autor como investigador integrante del Proyecto PIP CONICET n. ${ }^{\circ} 11220100100107$, La desigualdad Argentina en el largo plazo. Condiciones de vida $y$ derechos de propiedad en perspectiva comparada, siglos XVIII-XX, dirigido por el Dr. Jorge Gelman. Una primera versión de este estudio fue presentado (sin publicación en actas) en las XXIV Jornadas de Historia Económica realizadas en Rosario (Argentina) en 2014.
} 


\title{
Leasing and Inequality in the Highlands of Jujuy (Argentina) at the End of the $19^{\text {th }}$ Century
}

\begin{abstract}
Agrarian structures resulting from the most general processes of capitalist development and the redefinition of property rights in the Argentinean province of Jujuy in the $19^{\text {th }}$ century encouraged the consolidation of important large estates. The other side of this high concentration of land was the existence of a broad sector of the society composed by tenants. Several studies have highlighted the existence of a deeply unequal and conflictive society because of the unequal distribution of land. The objective of this article is to study tenants as producers, the wealth and gross income resulting from the rural exploitation under their responsibility in order to find out their remuneration capability while contrasting this information to other social situations. In order to attain this objective, we analyzed two cases where production relations were based on leasing factors. Based on fiscal and census sources in the 1890's containing data about agricultural and farming activities and on reports on profitability rates of the various agricultural or livestock products in the same decade, we reconstructed the gross income of these units for each of the actors involved and analyzed the inequality levels for this community.
\end{abstract}

Keywords: Argentina, Jujuy, large estates, tenants, inequality.

\section{Aluguel e desigualdade nas terras altas de Jujuy (Argentina) ao final do século XIX}

\section{Resumo}

As estruturas agrárias originadas nos processos mais gerais de desenvolvimento capitalista e de redefinição dos direitos de propriedade do século XIX na província argentina de Jujuy terminaram favoráveis a formação de importantes latifúndios. A outra face desta forte concentração de terra foi a existência de um amplo setor da sociedade que compartilhava a condição de arrendatários. Daí que neste artigo nos propomos a estudar os arrendatários como produtores - a riqueza e a renda bruta procedente da exploração rural da qual eram encarregados- a fim de indagar sua capacidade de remuneração, comparando-os entre si e com outras situações sociais. Para isso, analisamos os casos que tratam o assunto de suas relações de produção no aluguel. A partir de fontes fiscais e censitárias da década de 1890, que contém dados da atividade agropecuária e de informes sobre a rentabilidade dos distintos produtos de origem agrícola ou pecuária da mesma época, reconstruímos a renda bruta dessas unidades para cada um dos atores envolvidos e analisamos os níveis de desigualdade para este conjunto social.

Palavras-chave: Argentina, Jujuy, grande propriedade, arrendatários, desigualdade. 


\section{Introducción}

El proceso histórico de expansión del capitalismo en la provincia de Jujuy originariamente consolidó un modelo económico desigual en sus beneficios sociales y geográficos. En la región el polo capitalista decimonónico estuvo dado inicialmente por la producción azucarera, mediante la cual se conquistó el pujante mercado interno de la Argentina agroexportadora. En torno a esta actividad se conformó un complejo industrial de integración vertical -el ingenio plantación- caracterizado por unas unidades de producción autosuficientes que acapararon prácticamente toda la tierra cultivable circundante y asumieron las funciones del Estado y por la concentración de gran parte de los demás recursos disponibles ${ }^{1}$. Además, entre los factores explicativos de la reproducción de condiciones de desigualdad, ocupa un lugar central las formas de tenencia y de propiedad de la tierra, fundadas en el siglo XIX, que resultaron favorables a la consolidación de estructuras de propiedad latifundistas y/o tendencias a una alta fragmentación, generadora de minifundios. La estructura agraria configurada entonces refleja los efectos combinados de los procesos de ampliación de las fronteras sobre los territorios del oriente chaqueño y de la desamortización de la propiedad comunal indígena colonial andina, y su posterior mercantilización y privatización ${ }^{2}$.

Como consecuencia del privilegio minoritario de la propiedad de la tierra, su contracara fue la presencia de un actor eminente en las relaciones sociales y de producción rural: los arrendatarios. Este sector campesino dominó en los ambientes de altura propios de las zonas andinas, propensamente compelido a nutrir la fuerza de trabajo estacional de los ingenios situados en las llamadas tierras bajas. Claro que estamos hablando de un sujeto que la experiencia histórica del campo latinoamericano y argentino ha reproducido permanentemente. Pero no se trata de un sector homogéneo, pues ser arrendatario no dice nada sobre la posición social ni sobre el papel de la persona en la economía de la hacienda ${ }^{3}$.

Para el caso argentino la amplia literatura de revisión sobre los patrones del desarrollo agropecuario exportador pampeano durante el siglo XIX agrietó un conjunto de ideas preceptivas sobre el arrendamiento y los arrendatarios, propias de las visiones más tradicionales respecto de este tema. La minuciosa atención que se prestó al análisis y a la reconstrucción empírica de los actores partícipes de ese proceso ha sido clave en este sentido y resulta muy útil para analizar el tema aún en contextos no pampeanos. Hoy prima una imagen menos contraída al simple juego de pares opuestos (chacra agrícola/ minifundio/ arrendatario versus estancia ganadera/ latifundio/ terratenientes $)^{4}$.

\footnotetext{
${ }^{1}$ Lagos, Marcelo. "Estructuración de los ingenios azucareros jujeños en el marco regional (1870-1930)", en Campi, Daniel (coord.), Jujuy en la Historia, avances de investigación I (Jujuy: EDIUNJu, 1993), p. 122.

${ }^{2}$ Teruel, Ana y Fandos, Cecilia (2009). "Procesos de privatización y desarticulación de tierras indígenas en el Norte de la Argentina en el siglo XIX", en Revista Complutense de Historia de América, n. 35 , Universidad Complutense, Madrid, 2009, pp. 233-255.

${ }^{3}$ La frase corresponde a Jan Banzat citada por Fradkin, Raúl. "Reflexiones sobre historia agraria, regional y comparada: el arrendamiento de tierras de agricultura cerealera en la colonia tardía”, en Quinto Sol, n. ${ }^{\circ}$, Quilmes, Universidad Nacional de la Pampa, 1997, p. 56.

${ }^{4}$ Zeberio, Blanca. "La situación de los chacareros arrendatarios en la pampa húmeda. Una discusión inacabada” en Mandrini, Raúl y Reguera, Andrea (comps.), en Huellas en la tierra (Tandil: Tandil, 1993).
} 
Al retomar la noción de racionalidad limitada, Zeberio rastrea intensivamente las explotaciones de los arrendatarios de una zona de la provincia de Buenos Aires en pleno auge del capitalismo agrario para poner en duda que la distribución de la tierra bajo la forma de propiedad privada haya sido el factor decisivo de la estratificación social, y para concluir que lejos de comportarse como actores económicos exclusivamente ligados a la transferencia de renta, los arrendatarios fueron sujetos que elaboraron estrategias racionales. Consideramos que las visiones dicotómicas tan discutidas ya para la Pampa Húmeda, como la de terrateniente de tipo feudal/ campesino arrendatario, no han sido examinadas suficientemente con registros de orden empíricos en otras regiones de la Argentina decimonónica.

También en Jujuy los sectores arrendatarios constituyen uno de los núcleos centrales para la comprensión del desarrollo capitalista regional, típico de un territorio mediterráneo y especializado en la agroindustria azucarera. El proceso se liga indefectiblemente aquí a la desestructuración de la propiedad comunal indígena en plena vigencia hasta el inicio de la era republicana -con el creciente avance de la propiedad privada en su forma de gran hacienda rentística-, y la proletarización que afectó paulatinamente a una suficiente población campesina. Así, su importancia en el seno de las estructuras sociales de Jujuy es un fenómeno fecundo en la producción historiográfica y se lo ha examinado fundamentalmente a través de las formas de tenencia y de acceso a la tierra, y por las acciones de protestas que este grupo llevó a cabo históricamente 5 .

Por otra parte, en este artículo nos proponemos abordar otro costado de la población arrendataria, el de los productores y los propietarios de los bienes producidos, a fin de estimar la riqueza y alguna indicación de los ingresos procedentes de la explotación rural que tenían a su cargo. Nos interesa puntualmente develar niveles de estratificación, de desigualdad y las posibilidades de subsistencia del grupo. Para ello seleccionamos dos casos que resaltan las relaciones de producción en el arriendo, representativos de diferentes derechos de propiedad: se trata entonces, de las tierras públicas de la Puna y la hacienda privada en la Quebrada de Humahuaca.

\section{Puntos de vistas sobre el arrendamiento en las tierras altas jujeñas. Precariedad y proletarización}

Entre las condiciones geográficas de la provincia de Jujuy un factor de peso reconocido es la pluralidad ambiental que presenta. Una clásica división reconoce dos áreas centrales: las tierras altas y las tierras bajas. Sobre el extremo cordillerano se

\footnotetext{
${ }_{5}^{5}$ Madrazo, Guillermo. Hacienda y encomienda en los Andes. La Puna de Jujuy bajo el marquesado de Tojo, siglos XVII-XIX (Buenos Aires: Fondo Editorial, 1982). Paz, Gustavo. "Resistencia y rebelión campesina en la Puna de Jujuy, 1850-1875", en Boletín del Instituto de Historia Argentina y Americana Dr. Emilio Ravignani, vol. III, n. ${ }^{\circ}$ 4, Buenos Aires, Instituto de Historia Argentina y Americana Dr. Emilio Ravignani, 1991, pp. 63-89. Teruel, Ana. "La incidencia en la tenencia de la tierra en la formación del mercado de trabajo rural en la provincia de Jujuy. 1870-1910”, en Población \& Sociedad, n. ${ }^{\circ}$ 2, Tucumán, Fundación Yocabil, 1994, pp. 161-187. Teruel, Ana. "Estructuras agrarias comparadas: la Puna argentina y el sur boliviano a comienzos del siglo XX”, en Revista Mundo Agrario, vol. VI, n. ${ }^{\circ}$ 11, La Plata, UNLP, 2005, http://www.mundoagrario.unlp.edu.ar/article/view/v06n11a06/1298 (febrero 16 de 2015).
} 
ubican las llamadas tierras altas, conformadas por la Puna -un meseta de altura entre 3.000 y 4.000 metros sobre el nivel del mar-y por la Quebrada de Humahuaca -valle de altura con cordones montañosos entre los 2.000 y los 3.700 metros sobre el nivel del mar, en donde el clima es frío y seco y las precipitaciones no superan los $300 \mathrm{~mm}$ anuales-. En este sentido, se trata de un paisaje que ha condicionado históricamente las formas de asentamiento humano y también ha determinado el nivel de desarrollo de las actividades agropecuarias. A su vez, se plantean a las tierras bajas, las cuales presentan zonas de climas templados y terrenos a 1.200 metros sobre el nivel de mar y están conformada por la región de los Valles Centrales que fue el territorio escogido para el emplazamiento de la principal ciudad cabecera en la jurisdicción al producirse la conquista de la zona; y por las selvas tropicales de montaña y bosques andino, mas hacia el oriente de la provincia, en la región de los Valles Orientales que constituye el epicentro azucarero.

Mapa 1. Mapa cartográfico de Jujuy, Argentina.

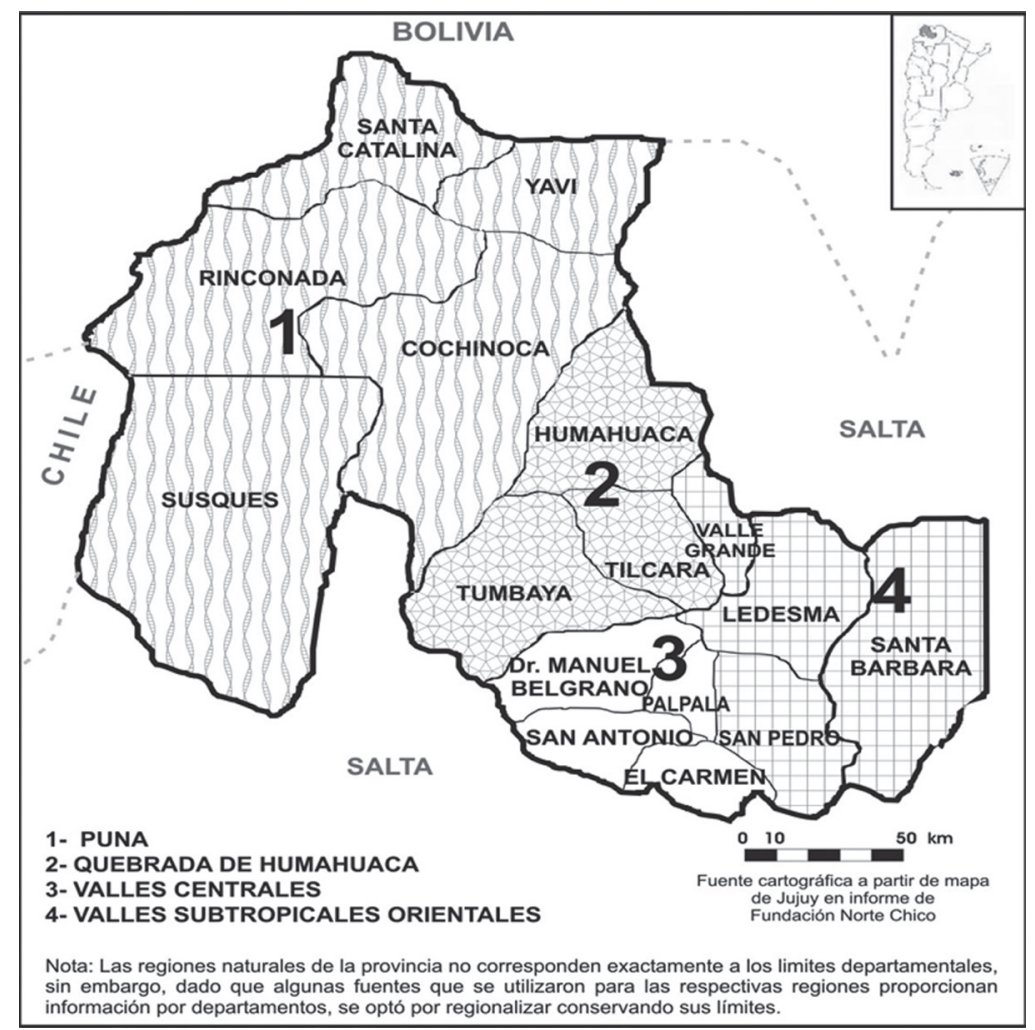

Fuente: Teruel, Ana. Problemas nacionales en escalas locales. Instituciones, actores y prácticas de la modernidad en Jujuy (Rosario, Prohistoria, 2010), p. 34.

El espacio social de las tierras altas, lugar que nos interesa en esta investigación, tuvo un activo rol en la época colonial como vía de circulación y de producción de las mercancías y los bienes que transitaban desde y hacia las minas del espacio peruano, además de constituir uno de los mayores reservorios de población indígena de la jurisdicción. Sin 
embargo, este sufrió a lo largo de siglo XIX procesos de despoblamiento y marginación socioeconómica. Esa situación se explicó primariamente por un modelo interpretativo que acentúa la incidencia de factores exógenos y que parte del reconocimiento de una fragmentación territorial entre regiones dinámicas e integradas al capitalismo -como fueron en el norte argentino las áreas de radicación de los ingenios azucareros-y entre regiones marginales productivamente pero tributarias forzosas de las primeras por su aportación de mano de obra ${ }^{6}$. Este último sería el caso de la Puna y la Quebrada de Humahuaca, donde su numerable población de origen indígena, pastores practicantes de una ganadería del autoconsumo y en menor medida, de una agricultura estival y de riego en pequeña escala, sin inserción competitiva en el mercado nacional ni el internacional y circunscritos a un sistema de intercambios de algunos excedentes de bienes complementarios para la reproducción familiar, fue definitivamente compelida a migrar a los polos de atracción azucareros.

Otros estudios puntualizan que la articulación al mercado del trabajo en los ingenios fue un desenlace posterior y alternativo al deterioro gradual de un espacio social vulnerable en la relación población y recursos naturales, lo cual fue afectado durante todo el siglo XIX por un círculo de factores endógenos -guerras, epidemias, sequías, presión fiscal y desatención pública- que provocaron crisis de mortandad y precariedad social. Uno de los síntomas más visibles de esas condiciones reinantes fue el despoblamiento creciente de la región?

Precisamente, los principales protagonistas de los procesos externos e internos que incidieron en las tierras altas fueron los grupos campesinos que en calidad de arrenderos ocupaban y trabajaban tierras fiscales y privadas. Puestos en la escena rural que brinda el marco de las haciendas de origen colonial, las explicaciones sobre la conformación, la condición social de arrendatarios y sus derroteros durante el siglo XIX expresan distintos puntos de vista.

Madrazo, por un lado, da cuenta de cómo las relaciones de producción basadas en el arrendamiento avanzaron inusitadamente desde la Independencia, y considera que tuvieron una dinámica socialmente desfavorable, dado que fueron empeorando las condiciones de vida de los sectores afectados por los recargos periódicos de las obligaciones de pago, el ensanchamiento de los servicios de trabajo, las penalizaciones y las prohibiciones jurídicas, más violentas y trágicas, sobre determinadas prácticas tradicionales. El cambio de contexto a partir de la Revolución incidió en los negocios mercantiles que unían la región a los polos mineros al recortar los ritmos y las demandas de las áreas agropecuarias abastecedoras. En consecuencia, las haciendas se refuncionalizaron, poniendo en un escalón más alto a la tierra como principal factor productivo y a la renta como principal beneficio económico. Para este autor, durante el siglo XIX la situación fue de infrasubsistencia y de explotación a un punto que llevó

\footnotetext{
${ }^{6}$ Rutledge, Ian. Cambio agrario e integración. El desarrollo del capitalismo en Jujuy. 1550-1960 (Tucumán: ECIRA-CICSO, 1987).

${ }^{7}$ Gil Montero, Raquel. "La Puna. Población, recursos y estrategias", en Teruel, Ana y Lagos, Marcelo (dirs.), Jujuy en la Historia de la colonia al Siglo XX (Jujuy: UNIHR-EDIUNJu, 2006).
} 
inexorablemente a los arrendatarios de las haciendas de las tierras altas de Jujuy a un estado de movilización permanente y a las sendas de la proletarización ${ }^{8}$.

Para Rutledge, el resultado en el largo plazo fue el mismo, dado que distingue una transformación gradual de semi siervo a arrendatario y luego, a semiproletario en una misma fracción social desde la colonia al siglo XX. En esta perspectiva, desde mediados del siglo XIX y hasta la década de 1930, el colono arrendero menguó su condición de siervo hasta obtener cierto margen de libertad en las haciendas, a la vez que pudo sostener un tono de lucha colectiva que constantemente afectó a las rentas de los propietarios, sobre todo las que llegaron a un nivel suficientemente exiguo. Desde esta perspectiva, se deduce que el bajo precio de los arriendos y la evasión generalizada minó los beneficios del sector terrateniente/rentístico, lo cual provocó la inviabilidad del sistema hacendario tradicional y obligó a los sectores propietarios a vender o a alquilar sus tierras a los ingenios azucareros, forzando a las poblaciones allí establecidas a servir como mano de obra en esa actividad agroindustrial ${ }^{9}$.

Una interpretación matizada proveniente del estudio de las interrelaciones entre las estructuras agrarias y la formación de un mercado de trabajo en Jujuy es la que nos proporciona Teruel. La autora detecta la existencia de áreas geográficas de mayor concentración de tierras (Puna y Valles Orientales) con distintos fines empresariales. En la Puna la impronta fue la percepción de la renta a través de la generalización de unidades de producción campesinas de arrenderos pastores. Afirma que la inmensa población sin tierra de la Puna y también la de los minifundios de la Quebrada de Humahuaca y de la zona de Valle Grande (donde fue factible la existencia de un campesinado en calidad de pequeño propietario), no desembocó irremediablemente en la proletarización sino que por el contrario, vía arriendo o parcela en propiedad, pudo mantener el acceso a los recursos de subsistencia y gozar de independencia y libertad para vincularse al mercado de productos y de trabajo ${ }^{10}$.

Con lo anterior, procuramos aportar a esta discusión, reconstruyendo los niveles de riqueza de la población arrendataria y determinando los indicadores de sus posibilidades de acumulación y/o subsistencia.

\section{Sobre los datos e indicadores. Aclaraciones metodológicas}

El análisis fundamental de este trabajo ha consistido en estimar riqueza e ingresos del sector productor arrendatario en dos tipos de propiedades (tierra fiscal y hacienda privada) en la geografía de las tierras altas. Para evaluar la riqueza y para obtener índices de distribución (en base al índice de Gini), hemos adoptado como unidad de medida el ganado en propiedad de cada sujeto listado en fuentes fiscales y censales. Conocemos que estas economías tenían una fuerte impronta ganadera, donde un porcentaje alto de los productores solo contaban entre sus bienes personales con las cabezas de ganado de su unidad familiar.

\footnotetext{
${ }^{8}$ Madrazo, Guillermo. Hacienda y encomienda... Op. Cit., pp. 165-167.

${ }^{9}$ Rutledge, Ian. Cambio agrario... Op. Cit., p. 194.

${ }^{10}$ Teruel, Ana. "La incidencia en la tenencia de la tierra en la formación del mercado de trabajo rural en la provincia de Jujuy. 1870-1910”, en Población \& Sociedad... Op. Cit., pp. 176-177.
} 
Por su parte, la renta de los arrendatarios estaba compuesta principalmente por el ingreso periódico de lo producido por ganado y/o cultivos. Consideramos que cualquier ingreso debe cumplir con la premisa de que sirva al consumo de una persona física o jurídica sin disminuir su riqueza (o patrimonio). La labor ha consistido en calcular la rentabilidad anual de acuerdo a los tamaños de cría ganadera y extensión de cultivos según las distintas especies.

\section{El indicador de riqueza}

La base primaria de información por la que hemos optado son las cédulas censales de 1895 y los boletines de agricultura y de ganadería de las propiedades estudiadas (tierras fiscales de Cochinoca y Hacienda de Huacalera) ${ }^{11}$, en las que se obtienen datos, en primer lugar, de la condición de arrendatarios, propietarios o medieros, y los nombres respectivos de los distintos cultivadores, la extensión general de la unidad agrícola y las superficies sembradas de distintas especies, además del mobiliario agrícola. Una dificultad constatada de esta información para la provincia de Jujuy es que presentan unidades de medidas completamente heterogéneas según diferentes territorios (cuadras cuadradas, hectáreas y áreas, metros cuadrados y leguas), no siempre se registra la extensión clasificada por cultivo, y muchas veces el propio censista escribe la palabra inutilizada por esas fallas de los registros. De las áreas estudiadas en esta oportunidad en Cochinoca era insignificante la producción agrícola y esta fuente no proporciona de manera desagregada la extensión por cultivos. En otros casos como en los relacionados con el registro en Huacalera, las superficies se expresan claramente en hectáreas y en áreas y se consigna la extensión afectada por cada especie ${ }^{12}$.

En segundo lugar, se trabajó con los listados de los productores ganaderos que proporcionan los boletines de ganadería, indicando para cada uno el número de cabezas que les correspondía por especie y contemplando solamente los siguientes rubros: ovinos, caprinos, vacunos, asnal y camélidos. Como lo que nos interesaba es trabajar la distribución a nivel de riqueza y no de tamaño de las crías, hemos traducido en valor de mercado vigente en 1904 las distintas cantidades de animales, con los siguientes precios: 25 pesos nacionales por cada vaca, cuatro pesos por cada oveja, 5 pesos por cada cabra, 16 pesos por cada burro y 6 pesos, la llama ${ }^{13}$. Con esta base de datos y con la información extraída de las cédulas censales del censo de población de 1895 sobre cantidad de familias y población del distrito de Huacalera y de Cochinoca, hemos realizado el estudio de distribución de riquezas, que mas adelante figura en el rubro "capital ganadero".

\footnotetext{
${ }^{11}$ Archivo General de la Nación (AGN), Documentos Escritos, Censos, Segundo Censo Nacional, año 1895, Boletín de Agricultura, n. ${ }^{\circ}$ 27, Departamento de Tilcara, fs. 206-211; Boletín de ganadería, n. ${ }^{\circ}$ 30, Departamento de Cochinoca, fs. 1 a 85, departamento de Tilcara, fs. 448-458.

${ }^{12}$ Aquí se han tomado esas medidas unificándolas del siguiente modo cuando eran menores a una hectárea: 0,25 hectáreas (a las comprendidas entre una y 40 áreas); 0,50 hectárea (entre 41 y 60 áreas); 0,75 hectárea (0,61 a 80 áreas).

${ }^{13}$ Holmberg, Eduardo. Investigación agrícola en la provincia de Jujuy (Jujuy: UNJu, 1988).
} 
Nuestra presunción sobre las relaciones de propiedad de la tierra dominantes implicaba el supuesto del predominio absoluto de arrendatarios en las áreas escogidas para el estudio, no obstante, hemos cotejado esa condición para la mayoría de los pobladores del universo analizado, con el cruce de los datos procedentes de las cédulas censales del boletín de Agricultura y el de Población del censo de 1895 (este último también establece la situación de propietarios para cada habitante), y con registros fiscales para el cobro de derechos impositivos ${ }^{14}$. Normalmente, la riqueza agrícola se adosa en los valores fiscales asignados a la propiedad de la tierra, como bienes inmobiliarios, cuestión que en nuestros casos ha sido de difícil tratamiento por la abrumadora mayoría de arrendatarios y muy escasos propietarios. Por esa razón, hemos tratado a la producción agrícola contabilizada en las cédulas censales de 1895 solo como base para estimar ingresos (y no riqueza en ese rubro).

\section{El indicador de ingresos}

Además de las estratificaciones sociales derivadas de la propiedad de ganado como bien rural, hemos querido profundizar sobre el análisis de los niveles de desigualdad según un registro estimable de los ingresos agrarios. La intención es lograr alguna indicación de la capacidad de remuneración de los distintos grupos de actores sociales (propietarios y arrendatarios, por ejemplo) que se puedan contrastar entre sí y con otras situaciones sociales. Nos hemos guiado, dentro de nuestras posibilidades de fuentes y del grado de avance en los conocimientos necesarios, con la propuesta metodológica para estudiar la desigualdad social rural catalana de mediados del siglo XIX de Garrabou, Planes, Saguer y Vicedo ${ }^{15}$. La clave del enfoque radica en una estimación de los ingresos netos que generaban los cultivos o las explotaciones en forma independiente al régimen de tenencia de la tierra, con el objetivo de reducir ese ingreso potencial a un multiplicador del salario anual de un jornalero.

Son necesarias algunas aclaraciones al respecto. En este avance de la propuesta se han calculado ingresos brutos indicativos y parciales de los actores rurales, no contamos por ahora con análisis sistemáticos de los costos y, por ende, de ingresos netos. Además, los rubros para medir los ingresos han sido los valores de lo producido anual y personalmente en concepto de producción de ovinos y de algunos cultivos (maíz, trigo y alfalfa). Por lo tanto, las cifras no muestran el ingreso de todos los cultivos y las especies de crías que cada uno tenía, ni mucho menos de otras actividades complementarias. Sin embargo, los tres rubros vegetales eran los más desarrollados en los espacios contemplados, y el ovino era central en estas economías pastoriles, como se detalla más adelante.

\footnotetext{
${ }^{14}$ Cédulas censales. Segundo Censo Nacional, Población, Argentina, 1895, Provincia de Jujuy, Departamentos de Cochinoca, http://search.labs.familysearch.org. Archivo Histórico de Jujuy (AHJ). Caja Documentos, año 1891, Departamento Tilcara, Avaluación para el cobro del derecho territorial, junio 8 de 1891.

${ }^{15}$ Garrabou, Ramón; Planas, Jordi; Saguer, Enric y Vicedo, E. Acceso a la propiedad y desigualdad social en el mundo rural catalán de mediados del siglo XIX, http://www.h-economica.uab.es/papers/ wps/2011/2011_01.pdf, (febrero 2 de 2015). No pretendemos equiparar nuestro trabajo, que es apenas exploratorio, con los fundados resultados de los investigadores europeos, sino ensayar la implementación de esos enfoques a las realidades y a las problemáticas regionales que nos interesan, adaptando en muchos puntos los procedimientos y los datos.
} 
Concretamente, los ingresos por cultivos se hicieron a partir de la nómina de todos los cultivadores que atañían al mismo de las planillas censales de 1895, donde como dijimos-se menciona la superficie cultivada con ese producto para cada uno, expresada en hectáreas. Con el cruce de los siguientes datos de 1904 del cuadro 1., se realizaron las cuentas:

Cuadro 1. Provincia de Jujuy. Relación rendimiento y precios productos agrícolas por hectárea.

\begin{tabular}{|c|c|c|c|}
\hline Especie & $\begin{array}{c}\text { Rendimiento } \\
\text { (anuales) }\end{array}$ & Precio & $\begin{array}{c}\text { Relación ingreso bruto anual/ } \\
\text { hectárea }\end{array}$ \\
\hline Trigo & $900 \mathrm{Kg}$ & $\begin{array}{c}\text { Un peso por } \\
1 \mathrm{Kg} .\end{array}$ & 90 pesos \\
\hline Alfalfa & 150 Quintales & $\begin{array}{c}2,50 \text { pesos } \\
\text { por quintal }\end{array}$ & 375 pesos \\
\hline Maíz & 160 Almudes & $\begin{array}{c}160 \text { pesos } \\
\text { por almud }\end{array}$ & 160 pesos \\
\hline
\end{tabular}

Fuente: elaboración propia sobre la base Holmberg, Eduardo. Investigación agrícola... Op. Cit., pp. 106, 136, 137 y 147.

Por su parte, las mismas planillas de los boletines de ganadería de 1895 sirvieron para delimitar el universo de productores de ovinos, para quiénes se consignan la cantidad de cabezas que cada uno tenía. Ello se cruzó con la siguiente información del año 1925: la productividad por cada majada de 100 ovejas era de 20 capones y 100 kilogramos de lana anuales, lo que nos permitió deducir el rendimiento de cada criador en esos rubros según el tamaño de su cría. Sobre esa base se estimó para el rendimiento de crías y de lanas separadamente, luego sumadas, que el ingreso según el precio de venta era de cada oveja a 4 pesos y el kilogramo de lana a 1,40 centavos ${ }^{16}$. Por consiguiente, una oveja produciría un ingreso bruto anual de 2,2 pesos. No nos resulta riesgoso este cotejo para determinar los valores de los rendimientos anuales, pues las condiciones tecnológicas de producción no sufrieron variaciones en el tiempo que se media entre la década de 1890 y la de 1920, las ecológicas se mantuvieron, aunque sí pudo haber habido distorsión en los precios.

También, hemos procurado trazar un cuadro de las superficies y del tamaño de las crías de animales estimables en la época para sortear líneas de pobreza, alcanzar niveles de subsistencia y/o de rentabilidad. Una primera base de medición procede de la propia política estatal de cesión gratuita de tierras fiscales a las familias indígenas de la Puna notoriamente pobres, por no ser propietarias de las parcelas de producción y que no alcanzaban las cincuenta cabezas de ganado menor, implementada en $1906^{17}$. Otra comprobación proviene de un proyecto de ley provincial de 1892 sobre vagos

\footnotetext{
${ }^{16}$ Salmoral, Dámaso y Villafañe, Jorge. Los Latifundios de la Puna. Informe de la Comisión encargada de estudiar dicho problema. Ley $n$. $^{\circ} 588$ (Jujuy, Imprenta del Estado, 1925), pp. 50-51.

${ }^{17}$ AHJ, Registro Oficial de Leyes, Ley n. ${ }^{\circ} 116$, agosto 25 de 1906, fs. 504; AHJ, Registro Oficial de Leyes, Reglamentación de la Ley de agosto 25 de 1906, 8 de noviembre de 1906, fs. 542.
} 
y arrenderos con el fin de obligarlos a conchabarse, delimitando como tales a los sujetos que no poseían ganados o cultivos suficientes para costearse su subsistencia y la de sus familias. En este se clasifica, en ese universo, a los arrendatarios que reunían menos de 100 cabezas de ganado mayor y/o menos de 300 de ganado menor. ${ }^{18}$ Con esta información y contemplando únicamente el número de cabezas de ganado ovino y sus equivalentes ingresos estimativos anuales, se han elaborado los cuadros 3 y 6 que se presentan más adelante.

Ha sido más difícil establecer parámetros similares para evaluar la situación de subsistencia o de acumulación en la producción agrícola por carencia de datos. El único antecedente coetáneo cierto, hallado en la investigación, es el que nos facilita Holmberg al indicar la máxima extensión posible de cultivo emprendida por un hombre ( $\sin$ trabajo extrapredial), una yunta de bueyes, un arado y una pala en el departamento de Tilcara para 1904, delineada en cuatro hectáreas ${ }^{19}$. En términos generales, ese sería el techo mayor alcanzado por una explotación campesina típica de la zona. Con esa escala hemos optado por clasificar las unidades productivas en máximas y en mínimas de acuerdo a la explotación lograda, y las que la superaban, de cuyo análisis resulta el cuadro 5 que incorporamos luego.

Una variable más retoma las referencias sobre otros ingresos como el de los jornaleros a fin de establecer algunas comparaciones. En este sentido, hemos recurrido al informe agrícola de 1904, en el que se estipula que los jornales mensuales en Jujuy rondaban los 15 pesos, más la ración diaria de alimentos, calculada en 0,50 centavos. En total, el ingreso mensual era de $30 \operatorname{pesos}^{20}$.

\section{Primer caso: el arriendo fiscal. Departamento Cochinoca}

Este caso involucra la jurisdicción completa del departamento de Cochinoca, con una superficie de $5.405 \mathrm{Km} 2$, situado en la región de la Puna jujeña. El área se asienta en los límites del colonial pueblo de indios de Casabindo y Cochinoca, establecido entre 1573 y 1602, donde ambas parcialidades étnicas obtuvieron derechos de propiedad comunal. Otro hito colonial de relevancia que afectó este territorio fue la constitución de la encomienda sobre esta población indígena, en 1654, a manos de Pablo Bernárdez de Ovando. Por su descendencia, esta encomienda se ligó a la propiedad de los marqueses de Tojo, desde 1700, fecha en que Juan José Campero y Herrera (yerno y heredero de Ovando) adquirió el título nobiliario.

Con el paso a la etapa republicana, la familia Ovando-Campero sostuvo derechos de propiedad sobre la tierra comunal de los pueblos de Casabindo y Cochinoca, lo cual constituyó una de las haciendas más extensas de la provincia. Respaldados y afirmados en la postura de que la encomienda figuraba con derechos de propiedad sobre la tierra, fue que estos actores transfiguraron las antiguas obligaciones tributarias

\footnotetext{
${ }^{18}$ Archivo Histórico de la Legislatura de Jujuy (AHLJ), Cajas Documentos, n. ${ }^{\circ} 48$, año 1892, Ley sobre vagos y arrenderos, enero 12 de 1892.

${ }^{19}$ Holmberg, Eduardo. Investigación agricola... Op. Cit., p. 71.

${ }^{20}$ Ibid., pp. 72 y 173.
} 
de los encomendados al pago de arriendos. Esa situación se sostuvo hasta la década de 1870, en que se inició el proceso de cuestionamiento de la legitimidad de esos títulos y las rebeliones de estos campesinos de la Puna ${ }^{21}$. El desenlace inicial del conflicto entre la familia Campero y sus arrendatarios fue el conocido fallo de la Corte Suprema de Justicia de 1877 por el que se declaró a estas tierras como fiscales. Con ese status permanecieron hasta la década de 1890, épocas en que comenzaron a ser privatizadas mediante la subasta pública a mejor postor.

Desde que se produjo la desvinculación de la familia Campero en la década de 1870 hasta que comenzaron las primeras compras de tierras fiscales de Cochinoca en la década de 1890, el arriendo fue la figura dominante de explotación y de tenencia de la tierra en la región. La primera disposición de administración de las mismas data de 1877 en que se instrumentó el pago al fisco de los arrendatarios del ex encomendero Fernando Campero, tomando como base la mitad del derecho que pagaban hasta entonces $^{22}$. Otra instancia de la administración de estas tierras se estableció con una nueva ley de 1880 (6 de abril), en la que se afirmó con claridad que las antiguas comunidades de los pueblos de Casabindo y Cochinoca eran dominio de la Provincia y que los productos de pastaje y arriendos conformaban un rubro específico de los ingresos público. Allí adquirió precisión el contrato de arrendamiento, que se estableció de acuerdo con el número de cabezas de ganado que poseía cada arrendatario, a quienes se les implementó la tasa de seis reales por cien ovejas, y medio real por cada ganado mayor ${ }^{23}$. Seis años después, se fijó una actualización de los precios del arriendo fiscal, consignando por primera vez valores en moneda nacional, en reemplazo del peso boliviano: por ciento de ovejas y cabras, 75 centavos, 14 centavos para ganados mayor, a regir en todos las tierras fiscales de la provincia ${ }^{24}$. Estas leyes permanecieron vigentes hasta la década de 1890 en que hubo un nuevo ajuste de las tasas por arriendo fiscal ${ }^{25}$ y en la que se sancionó la ley de ventas que organizó definitivamente la privatización.

Hay evidencias de las dificultades que enfrentaba el Estado en la administración de estos arriendos; lo que promovió la gestión de distintos ensayos para hacerlos más operativos, para racionalizar el cobro de los mismos; sin embargo, al final, cierta ineficacia obró a favor de la conveniencia de privatizar las tierras. Un año antes de la sanción de las leyes que instrumentaron las ventas en remate, en 1890, el gobernador de turno decía “[...] las extensas propiedades que en la Puna posee el fisco, dan una renta exigua si se tiene en cuenta el número de pobladores en ellas existentes y la cantidad de ganado

\footnotetext{
${ }^{21}$ Paz, Gustavo. "Resistencia y rebelión campesina en la Puna de Jujuy, 1850-1875”, en Boletín del Instituto de Historia... Op. Cit.

${ }^{22}$ Registro Oficial, compilación de Leyes y Decretos de la Provincia de Jujuy, tomo 3 (1887). Jujuy, Imprenta Tipográfica de José Petruzzeli, p. 326.

${ }^{23}$ Registro Oficial, compilación de Leyes y Decretos de la Provincia de Jujuy, tomo 3 (1887). Jujuy, Imprenta Tipográfica de José Petruzzeli, pp. 381-382.

${ }^{24}$ Registro Oficial, compilación de Leyes y Decretos de la Provincia de Jujuy, tomo 3 (1887). Jujuy, Imprenta Tipográfica de José Petruzzeli, pp. 628-629.

${ }^{25}$ AHJ, registro oficial, Ley mayo 22 de 1891, fs. 246. Establecía dos pesos por cada ciento de ovejas y cabras, 0,30 cvo por cabeza ganado vacuno, caballar, yeguarizo o mular y 0,25 por llama o burro.
} 
de su pertenencia"26. En 1887 se formó una comisión de estudios y exploración de los recuentos fiscales de la Quebrada y de la Puna. De esa acción ha quedado constancia de que en Cochinoca había 43 rodeos fiscales a cargo de tres comisarios, y que las irregularidades eran de distinto tipo. En primer lugar, se declara el acto ilegal de criadores de vacunos de los valles bajos, quienes usaban las tierras de pastaje fiscales para hacer rotación de pastos, utilizando los de las zonas altas en determinadas épocas del año sin pagar ningún derecho especial y provocando la privación de pastos para quienes eran los arrenderos de las propiedades fiscales. En segundo lugar, se expone sobre la constante violación del área delimitada y adjudicada para el pastaje, que:

Sucede que varios de los arrenderos que tienen una tropa de ganado lanar en el Rodeo A, por ejemplo, lo llevan diariamente al rodeo B, de lo cual resulta que los pastos del rodeo B se consumen y se hacen insuficientes para mantener la tropa de los ocupantes de dicho rodeo $[\ldots] .{ }^{27}$

En tercer lugar, se describe la práctica de un negocio privado relacionado con el pastaje en los terrenos fiscales arrendados, dado que los vecinos arrendatarios " [...] reciben tropas de animales a invernar (de los troperos que van en tránsito a Bolivia) en los lugares mas pastosos, cobrando para sí una cantidad mensual determinada”. Finalmente, se puntualizan las arbitrariedades de tipo clientelares de las que eran responsables las autoridades locales, quienes cometían desalojos o negaban el arrendamiento a ciertos sujetos para preferir a compadres, parientes o amigos.

Un dato certero del discurso del informe es que refleja la situación imperante de cierta laxitud en las prácticas del arriendo en las tierras fiscales, al menos de acuerdo con lo que pretendía el Estado respecto de ellas.

En el censo económico de 1895 que hemos consultado, figura muy bien el perfil de una población local mayoritariamente compuesta por arrendatarios; y el peso de la actividad pastoril, de una ganadería extensiva, diversificada en crías ovinas, caprinas, asnales y de llamas; con pocas explotaciones agrícolas de pequeña escala y de subsistencia. Solo a un 3\% de los actores de Cochinoca consignados en el censo de población y de ganadería le corresponde la categoría de propietarios. Las primeras compras efectuadas bajo la reglamentación de la ley de venta en subasta pública de 1893 datan de finales del año 1895 , por lo tanto, este proceso de transferencia es posterior al censo levantado en mayo de ese año, pilar de nuestro análisis. Por su parte, la referencia sobre producción agrícola en esta fuente es muy escueta, apenas unos 13 productores de unas 13 cuadras cuadradas, 12 de alfalfa y una de cebada, circunscripta a la zona de Quera, Chipaite y Cerro Blanco, todos en condición de "arrendatarios fiscales". ${ }^{28}$

En cuanto a la producción ganadera, los datos del censo permiten ubicar al departamento como el principal distrito caprino (el $28 \%$ de toda la provincia) y asnal (33\% del total); el segundo en relevancia por la cría de ovino (con el 20\% total),

\footnotetext{
${ }^{26}$ AHJ, mensaje del gobernador de la Provincia, el Sr. J. Zenarruza, año 1890, publicación oficial, Jujuy, p. 12.

${ }^{27}$ AHJ, caja documentos 2, año 1887, informe presentado al Gobierno en los recuentos de intereses fiscales de la Quebrada y Puna, mayo 25 de 1887.

${ }^{28}$ AGN, Segundo Censo Nacional, año 1895, Boletín de Agricultura, n. ${ }^{\circ} 27$, fs 1 .
} 
considerable menor significación del vacuno (2\%) y una importante presencia de llamas, con unas 6.588 cabezas.

De manera que este caso tratado es el de una economía fundamentalmente pastoril semi trashumante ${ }^{29}$, de cuya producción las unidades familiares se autoabastecían, realizaban sus intercambios (mediante venta o trueque) de carnes, lanas y cueros, y se procuraban de medios de transporte. Por su condición de arrendatarios, el ganado formaba para la mayoría de las familias el principal capital, al que se accedía al momento de constituirse una nueva familia. La importancia de la ganadería para esta sociedad también se deriva del hecho de que significaba la medida del pago de los arriendos ${ }^{30}$. Las actividades complementarias eran la extracción de sal de las salinas de Casabindo, la textil y la minera. A ello debe sumarse la arriería, en las que se empleaba a los animales de su propiedad, para movilizar parte de su producción, todo esto con el objetivo de generar un intercambio con productos complementarios ${ }^{31}$. En esta medida, los pobladores de la región de la Puna y de la Quebrada desarrollaban en gran medida la crianza de asnales y llamas por ser el principal medio de movilidad, constituyendo tropillas que tenían una organización diferente a las de mulas (siendo en la Puna un lujo la propiedad de mulas) $)^{32}$.

Al seguir el Estado propietario de las tierras de Cochinoca en la etapa de nuestro análisis, se plantea que más del $90 \%$ de sus ocupantes arrendatarios eran fiscales. Al respecto cabe preguntar ¿qué niveles de estratificaciones socieconómicas hemos constatado con el estudio de distribución de riqueza y las estimaciones de ingresos brutos de estos actores mayoritarios?

Cuadro 2. Departamento de Cochinoca. Distribución del capital ganadero. 1895.

\begin{tabular}{|c|c|c|c|c|c|c|}
\hline $\begin{array}{c}\text { N. }{ }^{\circ} \text { de } \\
\text { Criadores }\end{array}$ & $\begin{array}{c}\text { N. }{ }^{\circ} \text { de } \\
\text { Familias }\end{array}$ & $\begin{array}{c}\text { Capital } \\
\text { Máximo }\end{array}$ & $\begin{array}{c}\text { Capital } \\
\text { Mínimo }\end{array}$ & GINI/ UC & GINI/P & Relación 20- 20 \\
\hline 757 & 808 & 8.262 pesos & 24 pesos & 0,5053 & 0,472 & $51,4 \% / 3,39 \%$ \\
\hline
\end{tabular}

Fuente: elaboración propia sobre la base de AGN, Segundo Censo Nacional, año 1895, Cédulas censales, Legajo 180, Provincia de Jujuy, Boletín de ganadería, n. ${ }^{\circ}$ 30, Departamento de Cochinoca, fs. 1 a 85. Cédulas censales, Segundo Censo Nacional, Población, Argentina, 1895, Provincia de Jujuy, Departamentos de Cochinoca [on line] http://search.labs.familysearch.org. GINI/UC expresa el valor de este índice en relación a las familias censadas en 1895. GINI/P expresa el valor de este índice en relación a los propietarios de ganado según el pago de contribución inmobiliaria.

Dentro de las escalas de distribución de la riqueza que se manejan para otras realidades argentinas del siglo XIX, este universo social de Cochinoca, montado en torno al

\footnotetext{
${ }^{29}$ Para ello se requiere de la disponibilidad de un amplio, alternativo y móvil espacio en la oferta de los pastos y las aguadas naturales que permitan la reproducción del ganado.

${ }^{30}$ Gil Montero, Raquel. "La Puna. Población, recursos y estrategias”, en Teruel, Ana y Lagos, Marcelo (dirs.), Jujuy en la Historia... Op. Cit., p. 377.

${ }^{31}$ Conti, Viviana y Sica, Gabriela. Arrieros andinos de la colonia a la Independencia, http://nuevomundo. revues.org/60560 (diciembre 28 de 2014).

${ }^{32}$ Holmberg, Eduardo. Investigación agrícola... Op. Cit., p. 81.
} 
derecho de propiedad fiscal y la tenencia de la tierra por la vía del arriendo, revela un índice de desigualdad más equilibrado ${ }^{33}$. Incluso, dentro de los criadores arrendatarios de la región la desigualdad es aún menor, según lo revela la disminución del GINI sobre propietarios. Pese a ese inicial balance, resulta claro que los arrendatarios fiscales de Cochinoca constituían un sector heterogéneo, lo cual muestra contrastes interesantes de estratificación.

Gráfico 1. Departamento Cochinoca, 1895. Acumulación de cuotas por decil.

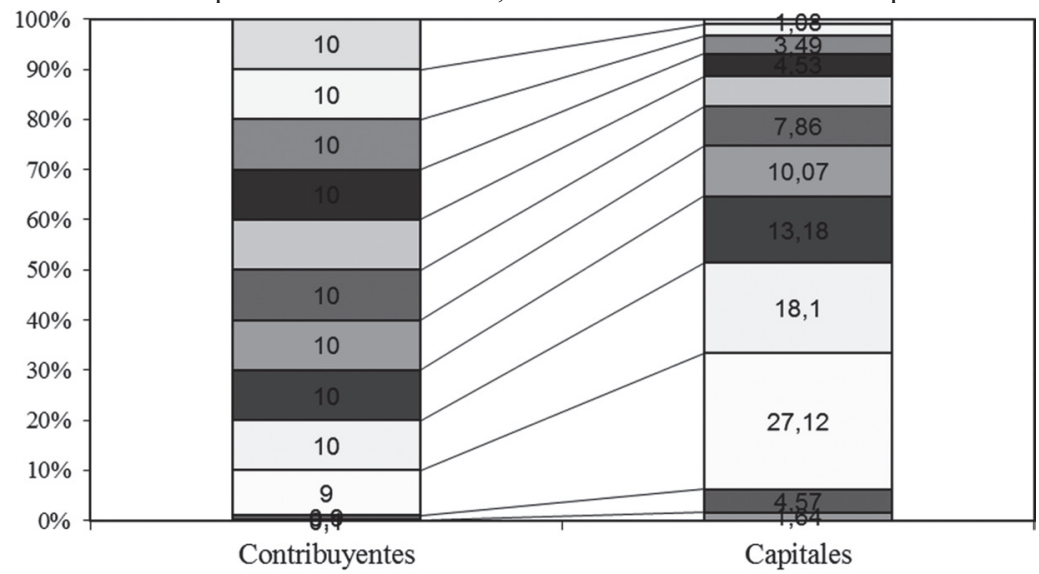

Fuente: elaboración propia sobre la base de AGN, Segundo Censo Nacional, año 1895, Cédulas censales, Legajo 180, Provincia de Jujuy, Boletín de ganadería, n. ${ }^{\circ}$ 30, Departamento de Cochinoca, fs. 1 a 85. Cédulas censales, Segundo Censo Nacional, Población, Argentina, 1895, Provincia de Jujuy, Departamentos de Cochinoca, http://search.labs.familysearch.org.

La primera noción que nos surge es que no todos ellos eran pobres. De hecho, en la relación 20/20, unos 150 sujetos de la fracción más rica congregaban un patrimonio ganadero superior a los 4.000 pesos, los cuáles quedan plasmados en el gráfico 1 de distribución de deciles con el control del $50 \%$ de la riqueza pecuaria de Cochinoca. No obstante, ese capital con el que contaban era muy inferior a los precios coetáneos de base establecidos para el remate de las tierras que ocupaban. Efectivamente, cuando se dispuso la venta en 1892, de los iniciales seis rodeos tasados, el más barato reportaba una valuación de 6.800 pesos, llegando algunos a 55.300 pesos $^{34}$. Con lo cual podemos señalar que solo cinco arrendatarios disponían de ese patrimonio en concepto de ganado, lo que prefigura la distancia que separaba a los grandes criadores arrendatarios del sector propietario. Luego, un universo suficiente conformaba un interesante sector intermedio compuesto por 300 sujetos con capital ganadero que iba desde los 1.000 a los 3.000 pesos aproximadamente, y que controlaban el 30\% del total de esos capitales. En otra escala, los sectores más pobres componían su riqueza con valores entre 900 y 24 pesos.

\footnotetext{
${ }^{33}$ Cf. Gelman, Jorge. "Desequilibrios regionales, desigualdades sociales. Las economías argentinas en el siglo XIX”, en Gelman, Jorge (coord.), El mapa de la desigualdad en la Argentina del siglo XIX, (Rosario: Prohistoria, 2011).

${ }^{34}$ AHJ, registro oficial, Decreto mayo 18 de 1892, Decreto de enajenación de las tierras fiscales de Cochinoca, fs. 395- 397.
} 
Arriendo y desigualdad en las tierras altas de Jujuy (Argentina) a fines del siglo XIX

Cuadro 3. Departamento de Cochinoca, 1895. Ingresos brutos por crianza y pastoreo de ganado ovino según tipos de establecimientos productivos.

\begin{tabular}{|c|c|c|c|}
\hline $\begin{array}{c}\text { Tipología de } \\
\text { establecimientos }\end{array}$ & $\begin{array}{c}\text { N. }{ }^{\circ} \text { de } \\
\text { Establecimientos }\end{array}$ & $\begin{array}{c}\text { Promedio de } \\
\text { ingreso }\end{array}$ & $\begin{array}{c}\text { \% de distribución } \\
\text { sobre criadores }\end{array}$ \\
\hline Tipo I & 63 & 1498 & 8,7 \\
\hline Tipo II & 78 & 762 & 11 \\
\hline Tipo III & 406 & 304 & 56 \\
\hline Tipo IV & 176 & 65,4 & 24,3 \\
\hline
\end{tabular}

Fuente: elaboración propia sobre la base de AGN, Segundo Censo Nacional, año 1895, Cédulas censales, Legajo 180, Provincia de Jujuy, Boletín de ganadería, $\mathrm{N}^{\circ}$ 30, Departamento de Cochinoca, fs. 1 a 85.

Recordemos que en el cuadro 3 solo hemos tenido en cuenta los ingresos por ganado lanar, buscando algún modo de indicación de tendencias generales. Los establecimientos de tipo I agrupan grandes unidades productivas, de más de 400 ovinos, cuyo promedio de ingreso resulta cuatro o más veces superior al ingreso anual de referencia seguida sobre salarios rurales, este grupo reunía el 32\% del capital ganadero de esta especie. Los establecimientos de tipo II congregan a unidades productivas ubicadas en las fronteras de la subsistencia con rebaños de 300 a 400 ovejas, condición que era reconocida por las autoridades como suficientes para vivir honestamente y quedar excluidos de la obligación del conchabo. Este grupo solo constituía el 11\% del total de criadores de Cochinoca y reportaban ingresos promedios dos veces superiores a los sectores asalariados. Agrupando estas dos categorías (I y II), en un total de $20 \%$ de los arrendatarios, encontramos que más del $60 \%$ los animales cargueros se encontraban en su poder, por lo que hay que considerar ingresos muchos mayores ligados a los servicios del transporte que podían brindar.

Los establecimientos de tipo III traduce el perfil de los ganaderos que podían asemejar sus ingresos procedentes de la cría y el pastoreo de ovinos a los salarios de jornaleros, quizás por ese rango compartido fue que se los consideró con bienes insuficientes para vivir autónomamente. La mitad de los productores arrendatarios de Cochinoca respondían a esa condición. Finalmente, con hatos inferiores a 50 ovejas (establecimientos del tipo IV) y reconocidos netamente como sectores pobres se hallaba el $25 \%$ de los criadores de la zona y los ingresos procedentes del pastoreo de ovejas resultaban más de cinco veces inferiores a los jornales anuales.

Si bien las dos categorías inferiores consideradas están por debajo del salario promedio anual de un peón, los contornos no son categóricos precisamente porque en esas unidades se desarrollaban actividades ganaderas complementarias y adicionadas a la exclusiva crianza de ovejas.

\section{Segundo caso: la hacienda arrendera. Finca Huacalera}

Este segudo caso aborda una propiedad ubicada en el departamento de Tilcara, en la región de la Quebrada de Humahuaca. Se trata de la hacienda de Huacalera configurada a partir de una merced colonial y que mantuvo practicamente intacta la superficie territorial originaria hasta avanzado el siglo XIX, pese a que había 
soportado sucesivos traspasos y readjudicaciones sucesorias. Esta constituía una unidad territorial de 50.048 hectáreas, la propiedad mejor valuada de toda la Quebrada de Humahuaca que presentaba un paisaje accidentado, pero que en "[...] sus fértiles valles prosperan el cultivo [...] de papas, trigo y sobre todo alfalfa, cuya calidad ha ganado lugar preferente en los mercados de consumo en donde obtiene precios superiores a un $40 \%$ sobre sus similares de la región llana" 35 .

La finca siempre estuvo poblada de numerosos arrendatarios, quienes "[...] en la reducida extensión que cultiva alrededor de su vivienda, y en las majadas que apacienta en las faldas circunvecinas" encuentra "los elementos necesarios de subsistencia [...] y ofrece en cambio como contribución usufructuaria, el trabajo de sus brazos" ${ }^{\text {"36. En }}$ 1910 se estipula que la renta anual proporcionada por el arriendo de estas tierras era de unos 18.000 pesos nacionales, procedente de unas 100 familias arrendatarias ${ }^{37}$.

Es importante señalar que las relaciones entre propietarios y arrenderos de esta hacienda atravesaron coyunturas de fuerte conflictividad durante la década de 1880 . Efectivamente, como una réplica de la lucha emprendida desde 1872 por los indígenas arrendatarios de Casabindo y Cochinoca se sucedieron rebeliones en distintas haciendas de la Quebrada, entre ellas Huacalera. Según describen los expedientes judiciales, en el año 1883 un grupo de sus arrendatarios fueron acusados -y finalmente expulsados de la finca- por incitar a un levantamiento generalizado, por negarse a la presentación para el rodeo convocado por el propietario, por oponerse al pago de arriendos y por desconocer los títulos de propiedad ${ }^{38}$. La voz colectiva de estos sujetos se entonó como una acusación a las desmejoradas condiciones del arrendamiento y a la usurpación de sus espacios productivos y habitacionales.

En este sentido, al ser una jurisdicción del departamento de Tilcara constituía un desarrollado distrito agrícola en términos relativos a los ambientes propios de las tierras altas. Se realizaban cultivos de riego, diversificados, en pequeña escala, que se combinaban con la cría de ganados y se complementaban con las actividades textiles y artesanales. Si bien la actividad económica respondía principalmente al impulso de la autosubsistencia familiar, eran factibles los excedentes que alimentaban un mercado reactivado a fines del siglo XIX y comienzos del XX, por la demanda de alimentos en los núcleos de construcción del ferrocarril y el despliegue minero de las borateras de la zona ${ }^{39}$. El cultivo de maíz y el trigo se desarrollaba en el $50 \%$ de las explotaciones de la hacienda de Huacalera, por lo general en predios promedio de una hectárea ${ }^{40}$. Se

\footnotetext{
${ }^{35}$ Archivo Histórico de Tribunales de Jujuy (ATJ), exp. 99, Deslinde y Mensura de Huacalera, año 1913, fs. $174 \mathrm{v}$.

${ }^{36}$ Ibid., fs. 175.

${ }^{37}$ AHJ, caja documento, n. ${ }^{\circ}$ 2, año 1910, exp. 21, M. Reclamo de la avaluación de la propiedad.

${ }^{38}$ Fandos, Cecilia. "Los sagrados derechos en cuestión. El conflicto por la tierra en las haciendas de la Quebrada de Humahuaca (Jujuy, Argentina), décadas de 1870 y 1880”, en Revista Andes, vol. VI, n. ${ }^{\circ} 26$, Salta, CEPHIA, 2015

${ }^{39}$ Holmberg, Eduardo. Investigación agrícola... Op. Cit., p. 72.

${ }^{40}$ AGN. Segundo Censo Nacional, año 1895, Cédulas censales, Boletín de Agricultura, n. ${ }^{\circ}$ 27, departamento Tilcara, fs. 206-2011.
} 
conoce que los derivados del maíz constituían productos fundamentales en la dieta cotidiana de la población, venían a satisfacer las necesidades locales y también servía para prácticas de trueque ${ }^{41}$. Un cultivo de tipo comercial donde Huacalera y todo el departamento de Tilcara tenían una destacada participación era la alfalfa, que servía para alimentación del ganado de viajeros e invernadas de tropas para Bolivia y Chile ${ }^{42}$.

En general, la producción ganadera de Tilcara era menos representativa en el cuadro provincial. Sin embargo, la mayoría de las unidades de producción contaban con crías de ovejas y de cabras que servían de complemento al sustento familiar como alimentación doméstica o para eventuales intercambios, con la presencia de un número ínfimo de establecimientos ganaderos de mayor envergadura. La finca Huacalera reunía en la década de 1890 el 14,5\% de las existencias de ganado ovino departamental, el 31\% del asnal, el 39\% del caprino y el 2,6\% del vacuno ${ }^{43}$.

Para este caso hemos analizado la distribución de riquezas y de ingresos, considerando el capital ganadero y los valores de rendimientos anuales por cultivos. El resultado se expresa en los cuadros y gráficos que siguen.

Cuadro 4. Hacienda de Huacalera. Distribución del capital ganadero y de los ingresos por cultivos, 1895.

\begin{tabular}{|c|c|c|c|c|c|c|c|}
\hline & $\begin{array}{c}\text { N. } \\
\text { Propiet. }\end{array}$ & $\begin{array}{c}\text { N. }{ }^{\circ} \\
\text { Familias }\end{array}$ & $\begin{array}{c}\text { Capital } \\
\text { Máximo }\end{array}$ & $\begin{array}{c}\text { Capital } \\
\text { Mínimo }\end{array}$ & GINI/UC & GINI/P & Relación 20- 20 \\
\hline $\begin{array}{c}\text { Ingreso } \\
\text { agrícola }\end{array}$ & 75 & 81 & 514.675 & 22,5 & 0,9684 & 0,9659 & $98,2 \% / 0,10 \%$ \\
\hline $\begin{array}{c}\text { Capital } \\
\text { ganadero }\end{array}$ & 94 & 81 & 6.564 & 5 & 0,4922 & 0,5624 & $60,1 / 2,57$ \\
\hline
\end{tabular}

Fuente: elaboración propia sobre la base de AGN. Segundo Censo Nacional, año 1895, Cédulas censales, Boletín de ganadería, n. ${ }^{\circ}$ 30, departamento de Tilcara, fs. 448- 458; Boletín de Agricultura, n. ${ }^{\circ} 27$, departamento Tilcara, fs. 206- 2011.

La extrema desigualdad que se advierte en los índices de Gini calculados por ingresos agrícolas resultan de la fuerte susripción en los cultivos que reunía la propietaria de esta hacienda. Como queda reflejado en el gráfico 2, el 93\% de esos ingresos le correspondían. Además del perfil rentístico de la finca, esa participación directa en una gama de cultivos, sobre todos los de tinte comercial como la alfalfa, denota también la intervención del hacendado propietario en la producción.

\footnotetext{
${ }^{41}$ Holmberg, Eduardo. Investigación agrícola ... Op. Cit., p. 147.

42 (Sin datos). Informe de la Inspección Nacional de Agricultura en la Provincia de Jujuy (Buenos Aires, 1875), p. 327.

${ }^{43}$ AGN. Segundo Censo Nacional, año 1895, Cédulas censales, Boletín de ganadería, n. ${ }^{\circ}$ 30, departamento de Tilcara, fs. 448-458.
} 
Gráfico 2. Hacienda de Huacalera. 1895. Acumulación de cuotas por decil de los ingresos agrarios.

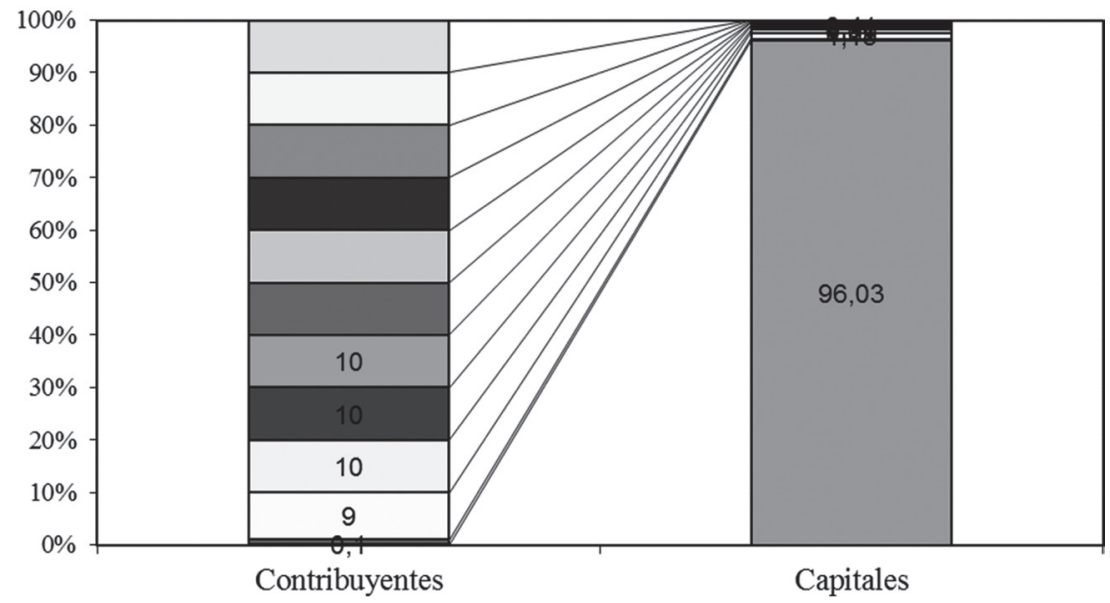

Fuente: elaboración propia sobre la base de AGN. Segundo Censo Nacional, año 1895, Cédulas censales, Boletín de ganadería, n. ${ }^{\circ}$ 30, departamento de Tilcara, fs. 448- 458; Boletín de Agricultura, n. ${ }^{\circ}$ 27, departamento Tilcara, fs. 206- 2011.

Los saltos de escalas con los productores agrícolas arrenderos que le siguen son muy amplios, el 9\% restante de los mejor posicionados controlaban solo un 1,5\% más de esos ingresos y comprometía a un grupo escaso con unidades agrícolas por encima de las dos hectáreas. Luego, el $90 \%$ de los arrendatarios participaban con un 2,4\% del valor total, creemos que en todos estos casos la práctica corriente era el uso de pequeñas extensiones circunscriptas a la residencia de estos sujetos, cuya ocupación no implicaba erogaciones por rentas pagadas al propietario, las que quedaban atadas solo a la actividad ganadera y a los servicios personales ${ }^{44}$.

Mucho más equitativo era el universo social implicado en las tareas de crianza y pastoreo de animales, con GINI cercanos 0,5. Campero de Mediana, dueña de la tierra, reunía el 10\% del capital ganadero y el nivel de concentración logrado en esta riqueza no era tan exagerado como en sector agrícola.

Sin embargo, al descontar su participación y al enfocar solo a los arrendatarios, vemos en el Gráfico 3 el mayor control del capital ganadero por el 9\% restante más rico: 33\% del total de los valores monetarios, e incluso el 19\% con mayores fortunas llegaba a reunir más del $50 \%$ del total. Esa fracción involucra a los sujetos que reunían mas de 1.000 cabezas de ganado. A un segmento intermedio del 30\% de los contribuyentes en escalas ascendentes les correspondía el 26\% más de los capitales considerados. El $50 \%$ restante comprendía a criadores con majadas inferiores a 300 animales, con un promedio de 182 per cápita.

\footnotetext{
${ }^{44}$ Madrazo señala que los arrendatarios contaban con algunas opciones excepcionales "Cualquiera de ellos podía obtener el dominio útil de la tierra para el trabajo agrícola [...], todo lo cual era concedido bajo la forma de dones gratuitos aunque, en realidad, debían ser retribuidos con trabajo [...]". Madrazo, Guillermo. Hacienda y encomienda... Op. Cit., p. 162.
} 
Gráfico 3. Hacienda de Huacalera, 1895. Acumulación de cuotas por decil de capital ganadero

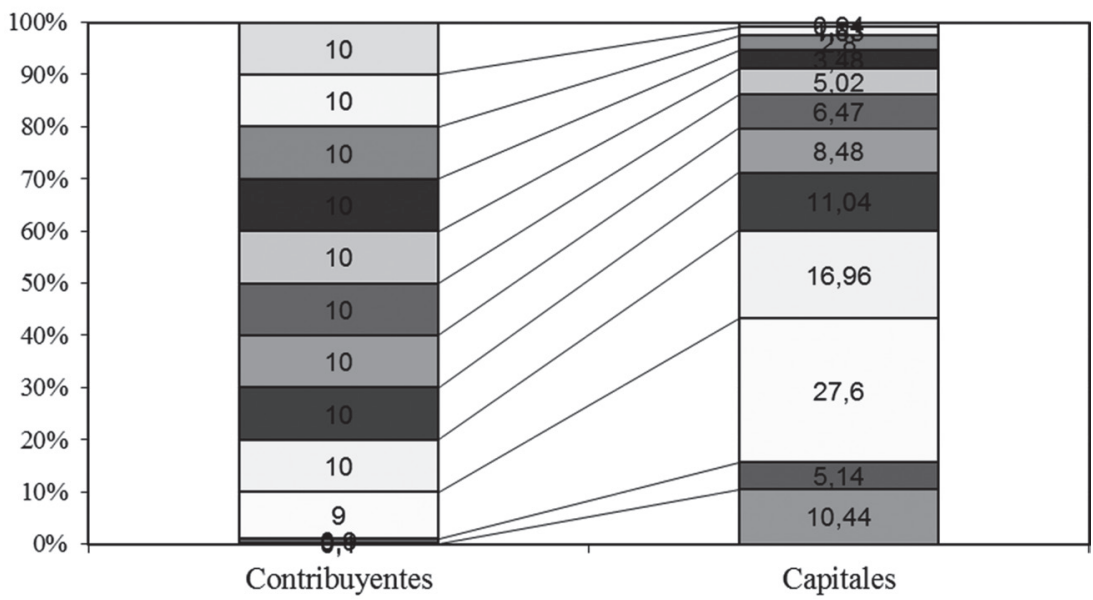

Fuente: elaboración propia sobre la base de AGN. Segundo Censo Nacional, año 1895, Cédulas censales, Boletín de ganadería, n. ${ }^{\circ}$ 30, departamento de Tilcara, fs. 448- 458; Boletín de Agricultura, n. ${ }^{\circ} 27$, departamento Tilcara, fs. 206-2011.

Cuadro 5. Hacienda de Huacalera. Ingresos por cultivo de alfalfa, maíz y trigo según tipos de establecimientos productivos, década de 1890

\begin{tabular}{|l|c|c|c|}
\hline \multicolumn{1}{|c|}{ Tipología de Unidades Productivas } & N. & $\begin{array}{c}\text { Promedio de } \\
\text { ingreso }\end{array}$ & $\begin{array}{c}\text { \% sobre } \\
\text { total de } \\
\text { productores } \\
\text { agrarios }\end{array}$ \\
\hline I. Hacienda (1391 hecáreas cultivadas) & 1 & 514675 & 1,3 \\
\hline $\begin{array}{l}\text { II. Arriendos de fracciones con explotación mayor a la } \\
\text { máxima (entre 5 y 6 hectáreas) }\end{array}$ & 1 & 1960 & 1,3 \\
\hline $\begin{array}{l}\text { III. Arriendos de fracciones con explotación máxima } \\
\text { (4 hectáreas) }\end{array}$ & 1 & 1285 & 1,3 \\
\hline $\begin{array}{l}\text { IV. Arriendos de fracciones con explotación mediana } \\
\text { (entre 2 y 3 hectáreas) }\end{array}$ & 10 & 648 & 13,3 \\
\hline $\begin{array}{l}\text { V. Arriendos de fracciones con explotación mínima } \\
\text { (1 hectárea o menos) }\end{array}$ & 62 & 186 & 82,6 \\
\hline
\end{tabular}

Fuente: elaboración propia sobre la base de AGN. Segundo Censo Nacional, año 1895, Cédulas censales, Boletín de Agricultura, n. ${ }^{\circ}$ 27, departamento Tilcara, fs. 206-211.

En la construcción de la tipología de las unidades de producción según los ingresos agrícolas que resume el cuadro 5, se advierte mejor el perfil de autosubsistencia del grueso de los cultivadores. Más del $80 \%$ de ellos realizaban explotaciones mínimas (tipo V) y sus ingresos brutos anuales era muy inferiores a los salarios de los jornaleros rurales, esos valores solo eran equiparables a la asignación de la ración diaria de alimentos de los peones: 0,50 centavos. Un 13\% de los productores agrarios 
corresponde al rango de fracciones de mediana explotación (tipo IV) con ingresos anuales promedio equivalentes a un duplo del jornal de los peones de campo. Los otros tipos contemplados en el cuadro no eran suficientemente representativos en el paisaje agrícola de la zona. Pero la hacienda de Huacalera, considerada como unidad productiva para su dueña, sin duda constituía un importante negocio agrícola, además de rentístico.

Respecto a los ingresos ganaderos, seguimos la misma clasificación ya hecha para el caso de Cochinoca (Cuadro 6). El gran establecimiento, con más de 500 cabezas de ovinos, corresponde Campero de Medina, afecta el 19\% de la rentabilidad total de la hacienda por esa especie cifra que triplicaba el salario rural anual y que era 30 veces superior al promedio de los ingresos del $83 \%$ de los arrendatarios pobres (los del tipo IV). Entonces, el grueso de los criadores arrenderos de Huacalera reunía rebaños que no superaban la línea de pobreza estipulada en la época que hemos seguido como indicador (50 o menos cabezas de ganado ovino), para alcanzar un ingreso anual promedio por este concepto diez veces menor al de los asalariados. Este grupo corresponde casi en un $100 \%$ con los labradores con superficies cultivadas de subsistencia (solo un caso no se ajusta a este patrón) y muchos de ellos (la mitad) eran exclusivamente criadores. El grueso de este grupo reunía considerables crías de cabras pero sabemos que este tipo de ganado cubría principalmente necesidades de subsistencia de las unidades familiares campesinas de las tierras altas.

Cuadro 6. Hacienda de Huacalera, 1895. Ingresos brutos por crianza y pastoreo de ganado ovino según tipos de establecimientos productivos.

\begin{tabular}{|c|c|c|c|}
\hline $\begin{array}{c}\text { Tipología de } \\
\text { establecimientos }\end{array}$ & $\begin{array}{c}\text { N. }{ }^{\circ} \text { de } \\
\text { Establecimientos }\end{array}$ & $\begin{array}{c}\text { Promedio de } \\
\text { ingreso }\end{array}$ & $\begin{array}{c}\text { \% de distribución sobre } \\
\text { criadores }\end{array}$ \\
\hline Tipo I & 1 & 1100 & \\
\hline Tipo II & & & 13 \\
\hline Tipo III & 9 & 280 & 83 \\
\hline Tipo IV & 55 & 39 & \\
\hline
\end{tabular}

Fuente: elaboración propia sobre la base de AGN. Segundo Censo Nacional, año 1895, Cédulas censales, Boletín de ganadería, . $^{\circ}$ 30, departamento de Tilcara, fs. 448-458.

\section{Cierre. Comparación y agenda}

El fenómeno del arrendamiento en Jujuy admite diversas realidades -que esperan ser abordadas con estudios específicos-, de las cuales hemos seguido dos tipos representativos. Por un lado, su adopción en las no muy pocas tierras fiscales que disponía -y dispone- el Estado provincial, el caso de Cochinoca. Por otro lado, el propio de una clásica hacienda de arrendatarios, de origen colonial, el caso de Huacalera.

Como síntesis de las principales tendencias reveladas con este estudio, podemos destacar la impronta productiva ganadera de las tierras fiscales de Cochinoca y el perfil más agroganadero de Huacalera. 
Centrémonos en un instante en la lectura que arrojan los datos de producción ganadera. En primer lugar, la desigualdad social derivada de la distribución de la riqueza ganadera (principal bien privado del que disponían estos arrenderos) era comparativamente más igualitaria que en otras situaciones de la Argentina decimonónica, y bastante similar en los dos universos que hemos tratado. En Huacalera, el hecho de tener entre los criadores a quien era la dueña de la tierra no llegaba a provocar mayores desajustes de riqueza, ni incidía en superiores índices de Gini en la distribución del capital por ganado.

En segundo lugar, la repartición de esa riqueza por deciles también evidencia comportamientos parecidos, con una leve diferencia en la concentración, dado que en Huacalera el 20\% más rico alcanzaba una cuota del $60 \%$ y en Cochinoca un $50 \%$. Sin embargo, ese mismo estrato en las tierras fiscales reunía un capital de 3.186 pesos promedio y en Huacalera 2.114 pesos. La tendencia general observada y confirmada es que los arrendatarios fiscales eran criadores más ricos que sus pares de la hacienda privada, incluso un grupo disponían de mayor capital ganadero que la propia Campero de Mediana (propietaria de Huacalera).

En tercer lugar, esta pauta vuelve a ser predominante si consideramos los ingresos originados a partir de la ganadería ovina. La agregación de unidades pecuarias que alcanzaban estándares de autosuficiencia y hasta de acumulación en Cochinoca (19\% del total) no se verificó con la misma intensidad en Huacalera donde, por el contario, más del $80 \%$ de sus criadores ni siquiera lograban los umbrales de la reproducción familiar a partir de los ovinos, aunque seguramente podían complementar con la cría de caprinos y con los cultivos de subsistencia.

Con seguridad, las condiciones del arriendo eran menos gravosas y coercitivas en las tierras fiscales que en las haciendas privadas. Según detallamos, el control del Estado sobre sus tierras y las rentas derivadas de ellas eran en muchos aspectos difíciles de concretar. Además de corroboradas situaciones de evasión de las obligaciones de pago de los arrendatarios fiscales y sin que ello implicara mayores penalizaciones, las rentas estaban claramente fijadas por la ley. En cambio, en las propiedades privadas las tasas de arriendo no estaban reguladas públicamente, de allí la gran disparidad de los precios que denunciaban las protestas recurrentes de los campesinos.

A continuación, algunas deducciones provistas por el análisis nos permiten hilar reflexiones de otro tipo. Cuando a partir de la década de 1920 tomó envergadura una propuesta oficial de expropiar los latifundios de la Puna ${ }^{45}$ para lograr un reparto más equitativo del recurso tierra, se realizaron diferentes inspecciones en el lugar, entrevistándose directamente a los protagonistas arrendatarios. Entre las expectativas que manifestaron algunos, contaba el deseo de que "el Gobierno compre

\footnotetext{
${ }^{45}$ Cf. Fleitas, María Silvia y Teruel, Ana. "Los campesinos puneños en el contexto de los gobiernos radicales: Políticas de tierras y conflictividad social en Jujuy", en Revista Estudios del ISHIR, vol. I, n. ${ }^{\circ}$, Rosario, ISHIR, 2011, pp. 102-123.
} 
las tierras y ellos les pagarán gustosos los arriendos equitativos de acuerdo con sus riqueza" ${ }^{46}$ como una alternativa a la otra propuesta de subdividir los latifundios para entregarlos fraccionados en propiedad privada individual a sus ocupantes. La primera pretensión reproducía la figura de tenencia entablada en Cochinoca cuando esas tierras pasaron a ser fiscales, como ya lo hemos tratado. En los argumentos esgrimidos a su favor en la década de 1920 se veía que esta era una forma de salvaguardar la justeza en el pago de las rentas y los terrenos en "comunidad, llevando sus ganados mezclados de un lado a otro a los terrenos propicios para la vida" ${ }^{47}$. De esta manera, creemos, entonces, que el arriendo fiscal fue tomando como la forma de una aspiración a futuro en la protesta social de estos campesinos, como producto de la propia experiencia (que les había significado gozar de ciertos márgenes de permisividad y un uso del territorio sin las demarcaciones rígidas impuestas en la propiedad privada). Sabemos, y lo hemos dicho, que esa suerte no fue la seguida en la mayoría de los campesinos de Cochinoca cuando estas tierras comenzaron a ser privatizadas desde 1895 .

Al retomar el caso de Huacalera, gravitaban mayores cargas en la renta, en la inspección, en la vigilancia y en las prohibiciones para el arrendero, condiciones de vida cotidiana que éstos repulsaron abiertamente en la década de 1880 . Vimos la gruesa presencia de un grupo de ellos que apenas rayaba la subsistencia ganadera, a lo que deben sumarse las asimetrías generadas en la actividad agrícola. Queda claro, siguiendo el caso, que los propietarios de las haciendas supieron añadir a los ingresos por renta de la tierra otros negocios, como el agrícola. Según exploramos, más del $90 \%$ de las cuotas de rentabilidad procedentes de los cultivos correspondían a la dueña de Huacalera, configurando un paisaje de absoluta desigualdad social en este plano y dejando un pequeño margen para la subsistencia de sus arrendatarios en el despliegue de esta actividad.

Somos consientes que en este estudio hemos efectuado apenas un recorte temporal y espacial para una realidad presente a lo largo del siglo XIX y comienzos del siglo XX, y que fue activa y cambiante según se fueron diagramando los derechos de propiedad en la provincia. La tarea pendiente es aún inmensa. Se impone en primer lugar, procurar estudios del tipo en la diacronía para indagar y para explicar los cambios y las continuidades sufridos por el sector de arrendatarios en ese proceso de más larga duración. En segundo lugar, al buscar siempre obtener variables para la comparación, es preciso ampliar la pesquisa de otras fisonomías regionales del fenómeno del arrendamiento, como de hecho existió en las grandes propiedades de las "tierras bajas" jujeñas, para realizar comparaciones. Finalmente, no debe prescindirse de la búsqueda de los indicadores necesarios en la agenda futura, que afinen componentes de ingresos rurales, incorporando, por ejemplo, la totalidad de las especies ganaderas que se producían.

\footnotetext{
${ }^{46}$ Salmoral, Dámaso y Villafañe, Jorge. Los Latifundios de la Puna. Informe de la Comisión encargada de estudiar dicho problema. Ley $n .{ }^{\circ} 588$ (Jujuy: Imprenta del Estado, 1925), p. 46.

${ }^{47}$ Ibid., p. 46.
} 


\section{Fuentes}

\section{Fuentes primarias}

\section{Archivos}

Archivo Histórico de Jujuy (AHJ), mensaje del gobernador de la Provincia, el Sr. J. Zenarruza (publicación oficial), Jujuy, 1890.

\section{Libros}

Salmoral, Dámaso y Villafañe, Jorge. Los Latifundios de la Puna. Informe de la Comisión encargada de estudiar dicho problema. Ley $n .^{\circ} 588$. Jujuy: Imprenta del Estado, 1925.

\section{Fuentes secundarias}

\section{Libros}

Holmberg, Eduardo. Investigación agrícola en la provincia de Jujuy. Jujuy: UNJu, 1988.

Madrazo, Guillermo. Hacienda y encomienda en los Andes. La Puna de Jujuy bajo el marquesado de Tojo, siglos XVII-XIX. Buenos Aires: Fondo Editorial, 1982.

Rutledge, Ian. Cambio agrario e integración. El desarrollo del capitalismo en Jujuy. 1550-1960. Tucumán: ECIRA-CICSO, 1987.

\section{Capítulos de libros}

Gelman, Jorge. "Desequilibrios regionales, desigualdades sociales. Las economías argentinas en el siglo XIX", en Gelman, Jorge (coord.), El mapa de la desigualdad en la Argentina del siglo XIX. Rosario: Prohistoria, 2011.

Gil Montero, Raquel. "La Puna. Población, recursos y estrategias”, en Teruel, Ana y Lagos, Marcelo (dirs.), Jujuy en la Historia de la colonia al Siglo XX. Jujuy: UNIHREDIUNJu, 2006.

Lagos, Marcelo. "Estructuración de los ingenios azucareros jujeños en el marco regional (1870- 1930)", en Campi, Daniel (coord.), Jujuy en la Historia, avances de investigación I. Jujuy: EDIUNJu, 1993.

Zeberio, Blanca. "La situación de los chacareros arrendatarios en la pampa húmeda. Una discusión inacabada", en Mandrini, Raúl y Reguera, Andrea (comps.), en Huellas en la tierra. Tandil: Tandil, 1993. 


\section{Artículos en revistas}

Fandos, Cecilia. "Los sagrados derechos en cuestión. El conflicto por la tierra en las haciendas de la Quebrada de Humahuaca (Jujuy, Argentina), décadas de 1870 y 1880”, en Revista Andes, vol. 6, n. ${ }^{\circ}$ 26, 2015.

Fleitas, María Silvia y Teruel, Ana. "Los campesinos puneños en el contexto de los gobiernos radicales: Políticas de tierras y conflictividad social en Jujuy, en Revista Estudios del ISHIR, vol. I, n. ${ }^{\circ}$ 1, 2011.

Fradkin, Raúl. "Reflexiones sobre historia agraria, regional y comparada: el arrendamiento de tierras de agricultura cerealera en la colonia tardía", en Quinto Sol, n. ${ }^{\circ} 1,1997$.

Paz, Gustavo. "Resistencia y rebelión campesina en la Puna de Jujuy, 1850-1875”, en Boletín del Instituto de Historia Argentina y Americana Dr. Emilio Ravignani, vol. III, n. ${ }^{\circ} 4,1991$.

Teruel, Ana y Fandos, Cecilia. "Procesos de privatización y desarticulación de tierras indígenas en el norte de Argentina en el siglo XIX", en Revista Complutense de Historia de América, n. ${ }^{\circ}$ 35, 2009.

Teruel, Ana. "La incidencia en la tenencia de la tierra en la formación del mercado de trabajo rural en la provincia de Jujuy. 1870-1910", en Población \& Sociedad, n. ${ }^{\circ}$ 2, 1994.

\section{Publicaciones en internet}

Conti, Viviana y Sica, Gabriela. Arrieros andinos de la colonia a la Independencia, http://nuevomundo.revues.org/60560.

Garrabou, Ramón; Planas, Jordi; Saguer, Enric y Vicedo, E. Acceso a la propiedad $y$ desigualdad social en el mundo rural catalán de mediados del siglo XIX, http:// www.h-economica.uab.es/papers/wps/2011/2011_01.pdf.

Teruel, Ana. "Estructuras agrarias comparadas: la Puna argentina y el sur boliviano a comienzos del siglo XX", en Revista Mundo Agrario, vol. VI, n. ${ }^{\circ}$ 11, http://www. mundoagrario.unlp.edu.ar/article/view/v06n11a06/1298. 